Case Report

\title{
New Parameter for In-Office Dental Bleaching
}

\author{
Cristina Dupim Presoto, ${ }^{1}$ Janaina Freitas Bortolatto, ${ }^{1}$ \\ Priscila Petrucelli Freire de Carvalho, ${ }^{1}$ Tamara Carolina Trevisan, ${ }^{1}$ \\ Michael Christopher Floros, ${ }^{2}$ and Osmir Batista de Oliveira Junior ${ }^{1}$ \\ ${ }^{1}$ Department of Restorative Dentistry, Araraquara Dental School, Universidade Estadual Paulista (UNESP), \\ 1680 Humaitá Street, 14801-903 Araraquara, SP, Brazil \\ ${ }^{2}$ Departments of Physics \& Astronomy and Chemistry, Trent Centre for Biomaterials Research, Trent University, \\ Peterborough, ON, Canada K9J 7B8
}

Correspondence should be addressed to Cristina Dupim Presoto; crispresoto@hotmail.com

Received 29 March 2016; Accepted 17 May 2016

Academic Editor: Michelle A. Chinelatti

Copyright (c) 2016 Cristina Dupim Presoto et al. This is an open access article distributed under the Creative Commons Attribution License, which permits unrestricted use, distribution, and reproduction in any medium, provided the original work is properly cited.

Dental bleaching is considered a conservative and biologically safe treatment for discolored teeth. Despite this, one of the major undesirable effects of bleaching is dentin sensitivity which may occur during and after treatment. To address these sensitivity issues, new dental bleaching preparations with lower concentrations of hydrogen peroxide $\left(\mathrm{H}_{2} \mathrm{O}_{2}\right)$ have recently been introduced to the market. This paper presents a clinical case report of a 20 -year-old female patient admitted to the Araraquara Dental School, UNESP, Brazil. The patient underwent dental bleaching using one of the new products with reduced hydrogen peroxide concentration, Lase Peroxide Lite $6 \%$, a $6 \% \mathrm{H}_{2} \mathrm{O}_{2}$ gel containing titanium oxide nanoparticles doped with nitrogen $\left.\left(6 \% \mathrm{H}_{2} \mathrm{O}_{2} / \mathrm{N} \text {-doped TiO}\right)_{2}\right)$.

\section{Introduction}

The demand for aesthetic dentistry has increased continuously [1-4], and the smile's appearance has become an important part of the social attractiveness of a person and their interactive communication skill $[1,2,4,5]$.

Currently, dental bleaching has been recognized as an effective method for the treatment of discolored teeth, being considered a conservative and biologically safe type of treatment $[4,6-9]$.

Hydrogen peroxide $\left(\mathrm{H}_{2} \mathrm{O}_{2}\right)$ is a chemical substance with high oxidative power and is the most widely used agent for in-office teeth whitening at concentrations ranging mainly from 25 to 35\% [10-13]. Peroxide agents are highly unstable and when in contact with the tissue, they dissociate into water, oxygen, and free radicals, the latter accounting for the observed bleaching effect due to their ability to oxidize organic pigments [9]. It is known that the diffusion of $\mathrm{H}_{2} \mathrm{O}_{2}$ through the dentin depends on the concentration of the gel, the period of time that the agent is in contact with the tooth [13], and the thickness of the dental structure $[8,14]$.
One of the major undesirable effects of bleaching is tooth sensitivity $[4,7,9,12,13,15-18]$ that occurs during and after the treatment and may represent a degree of biological damage to the dentin-pulp complex [4, 7, 9, 13, 15-17]. There are many factors that are known to increase sensitivity, such as high concentrations of $\mathrm{H}_{2} \mathrm{O}_{2}$, high enamel permeability, prolonged use of bleaching agents, heat during application through accelerator lamps, and differences in the structural morphology of enamel and dentin with pores which facilitate the infiltration of bleaching $[8,12,15,16]$. Sensitivity issues have led some manufacturers to release bleaching gels with lower concentrations of $\mathrm{H}_{2} \mathrm{O}_{2}$ in order to minimize the side effects produced by peroxide radicals $[9,13,17]$.

Aiming to increase both efficacy and safety, new bleaching agents with lower concentrations of $\mathrm{H}_{2} \mathrm{O}_{2}$ based on the catalytic action of a nanoparticle semiconductor additive such as titanium dioxide $\left(\mathrm{TiO}_{2}\right)$ activated by light sources $[9,16-20]$ are now entering the market $[4,9,13,16-$ 20]. A significant reduction in the sensitivity of bleaching treatments which use nitrogen doped titanium dioxide and $15 \% \mathrm{H}_{2} \mathrm{O}_{2}$ concentration has been reported in the literature 


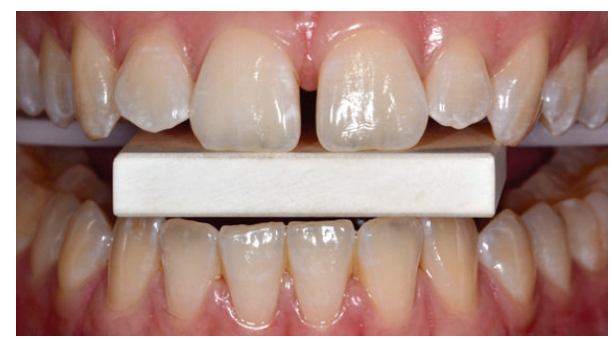

FIgURE 1: Initial picture taken with calibration block.

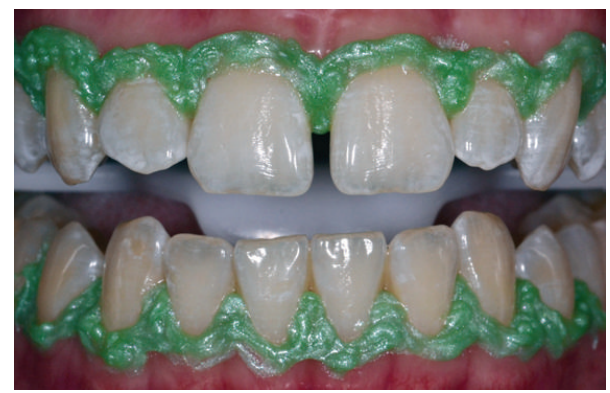

FIGURE 2: Gingival barrier properly applied and light-cured.

$[8,9,16-18]$. Nevertheless, bleaching agents with $6 \% \mathrm{H}_{2} \mathrm{O}_{2}$ / $\mathrm{N}$-doped $\mathrm{TiO}_{2}$ are innovative and significantly lower in peroxide concentration and, to our knowledge, there are few clinical studies evaluating in-office tooth bleaching with agents at this concentration $[17,18]$. Thus, this study aims to present a case report using this new product.

\section{Case Presentation}

A female patient, PPFC, 20 years old, attended the Operative Dentistry Clinic at Araraquara Dental School, UNESP, Brazil, and reported dissatisfaction with the aesthetics of her anterior teeth. Despite the midline diastema between central incisors, the factor that most bothered her was the color of her teeth. During the clinical exam, there were no factors observed which would contraindicate the use of tooth bleaching. As the patient was young, we decided to use a bleaching agent with a minimal $\mathrm{H}_{2} \mathrm{O}_{2}$ concentration. We used a new product, Lase Peroxide Lite $6 \%\left(6 \% \mathrm{H}_{2} \mathrm{O}_{2} / \mathrm{N}\right.$-doped $\left.\mathrm{TiO}_{2}\right)$ (DMC Equipment, São Carlos, SP, Brazil), which is activated by a light source. The light source used was a Whitening Lase II (DMC Equipment, São Carlos, SP, Brazil), a new type of inoffice photocatalytic equipment composed of six violet LEDs (405 nm wavelength) and three infrared lasers $(808 \mathrm{~nm}$ ).

Before beginning the treatment, initial photography with a ceramic block for calibration was performed and retained for subsequent analysis using ScanWhite, a specific software program for the objective assessment of tooth bleaching levels based on computational processing of digital images (Figure 1). Subsequently, professional dental prophylaxis was performed with a Robinson brush with a pumice and water paste. A gingival barrier (Lase Protect, DMC, São Carlos, SP, Brazil) was then applied and light-cured for 10 seconds for each dental element (Figure 2).

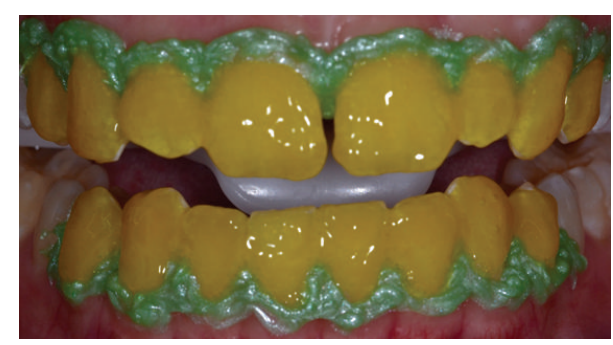

FIGURE 3: Bleaching gel applied to the buccal surface of the upper and lower teeth.

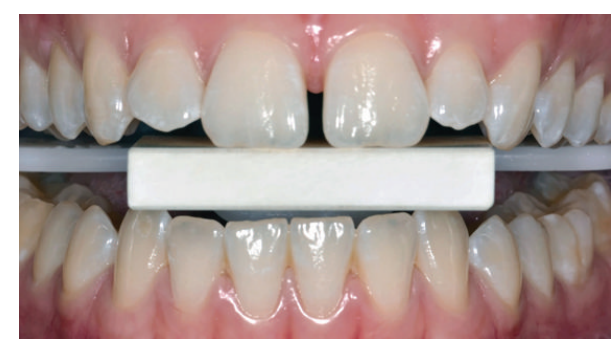

FIGURE 4: Final picture taken with calibration block.

The bleaching agent was mixed and applied in homogeneous layers on the buccal surfaces of the upper and lower anterior teeth (Figure 3). The $6 \% \mathrm{H}_{2} \mathrm{O}_{2} / \mathrm{N}$-doped $\mathrm{TiO}_{2}$ gel is provided in two phases, a peroxide and a thickener, which should be mixed in proportions of 3 drops of peroxide for 1 drop of thickener. In this case, for whitening the upper and lower arches until the premolars region, we used a total of 18 drops of peroxide and 6 drops of thickener. After the gel's application, it was kept in contact with dental surface for 12 minutes and photocatalyzed by LED/laser light, alternating the irradiation between the upper and lower arches every minute. Afterwards, the bleaching gel was removed and a new application sequence was performed. Three clinical sessions were held with two application cycles of the bleaching agent in each of them and a 7-day interval between the sessions.

One week following the end of the bleaching treatment, a new photography session was performed with the same calibration block (Figure 4). The initial and final images were compared in ScanWhite to determine how much the teeth responded to the whitening procedure. The images were first transmitted to the software and a calibration was performed. Next, for each picture, an area was selected in the middle third of labial surface of the anterior teeth. The result showed 22 tones of whitening for the upper right central incisor and 50 tones for the right canine (Figure 5). The patient reported that she was very satisfied with the final color of her teeth.

Tooth sensitivity was measured by a visual analogue scale (VAS), which provides a range of scores from 0 to 100 , where 0 represents no pain and 100 represents extreme pain. At the end of each clinic session, the patient was asked to mark on the scale their perceived sensitivity both during and after the session. She reported sensitivity only during the first application in the second session and this was classified as 


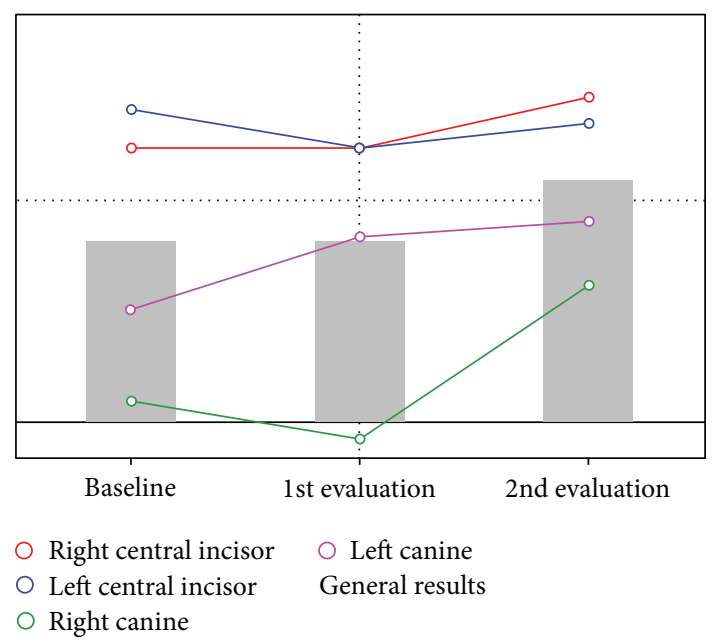

FIGURE 5: Overall result of bleaching.

low, with an intensity of $20 \%$ in a shock sensation and with a 1-second duration.

\section{Discussion}

The presence of sensitivity to bleaching treatments with high concentration gels and the search for an alternative with both efficacy and safety were the main reasons why bleaching agents with lower concentrations of $\mathrm{H}_{2} \mathrm{O}_{2}$ were introduced to the market $[4,8,13,17,18]$. Initially, it was believed that a high concentration gel and long contact time with dental structure would be required to obtain greater efficacy with bleaching procedures $[9,21]$. Nonetheless, the use of $15 \%$ $\mathrm{H}_{2} \mathrm{O}_{2} / \mathrm{TiO}_{2}$ photocatalyzed by LED was recently reported and demonstrated that, besides having lower sensitivity compared to products with $35 \%$ concentration, this preparation also provided greater bleaching efficacy $[8,9,16,17,20]$. We also observed this finding in the clinical case presented here using a preparation with only $6 \% \mathrm{H}_{2} \mathrm{O}_{2}$.

The presence of $\mathrm{N}$-doped $\mathrm{TiO}_{2}$ semiconductor allows a reduction in the required concentration of $\mathrm{H}_{2} \mathrm{O}_{2}$, which improves the biocompatibility of the final product by significantly reducing dental sensitivity during and after the procedure, directly increasing the safety of the whitening procedure $[9,17-19]$. By incorporating $\mathrm{N}$-doped $\mathrm{TiO}_{2}$ nanoparticles, it is necessary to photocatalyze the gel with a light source in order to improve its action. This new class of bleaching agents is safer and effective for promoting bleaching with a reduced concentration of free radical peroxides, thereby minimizing damage to the tooth structure [22].

In a clinical study using a $6 \% \mathrm{H}_{2} \mathrm{O}_{2}$ varnish system for in-office whitening, da Mata and Marques [10] reported that none of the patients showed any sensitivity, which was a common side effect upon using gels with high peroxide concentrations. By using a $6 \% \mathrm{H}_{2} \mathrm{O}_{2}$ varnish, Calatayud et al. [23] also demonstrated that the application of the gel showed significant clinical efficacy when applied to in-office bleaching and also when applied by patients themselves at home.
In the clinical case described in this paper, upon comparing the results before and after the bleaching procedure, the choice for central incisors and canines teeth was done to ensure a more homogeneous sample, as central and lateral incisors usually have the same color and, together, could distort the results of the hemiarch's mean score [23-25]. In Figure 5, a major color alteration is observed for the canines when compared to central incisors. The results showed that the use of these new bleaching gels provides color alteration needed for patient satisfaction in addition to lowering dental sensitivity. Therefore, this case reported a successful bleaching treatment for young patients, combining the great aesthetic results, as desired by patients, and also improved biocompatibility and safety from a lower concentration of bleaching gel.

\section{Consent}

The authors declare that the patient gave her informed consent for the case report to be published.

\section{Competing Interests}

The authors declare that there is no conflict of interests regarding the publication of this paper.

\section{References}

[1] F. N. Hattab, M. A. Qudeimat, and H. S. Al-Rimawi, "Dental discoloration: an overview," Journal of Esthetic Dentistry, vol. 11, no. 6, pp. 291-310, 1999.

[2] A. Joiner, "Tooth colour: a review of the literature," Journal of Dentistry, vol. 32, no. 1, pp. 3-12, 2004.

[3] S. B. Mehta, S. Banerji, and R. Aulakh, "Patient assessment: preparing for a predictable aesthetic outcome," Dental Update, vol. 42, no. 1, pp. 78-86, 2015.

[4] C. Kose, A. Calixto, J. Bauer, A. Reis, and A. Loguercio, "Comparison of the effects of in-office bleaching times on whitening and tooth sensitivity: a single blind, randomized clinical trial," Operative Dentistry, vol. 41, no. 2, pp. 138-145, 2016.

[5] S. T. Henson, S. J. Lindauer, W. G. Gardner, B. Shroff, E. Tufekci, and A. M. Best, "Influence of dental esthetics on social perceptions of adolescents judged by peers," American Journal of Orthodontics and Dentofacial Orthopedics, vol. 140, no. 3, pp. 389-395, 2011.

[6] B. A. Matis, Y. Wang, T. Jiang, and G. J. Eckert, "Extended athome bleaching of tetracycline-stained teeth with different concentrations of carbamide peroxide," Quintessence International, vol. 33, no. 9, pp. 645-655, 2002.

[7] J. E. Dahl and U. Pallesen, "Tooth bleaching-a critical review of the biological aspects," Critical Reviews in Oral Biology and Medicine, vol. 14, no. 4, pp. 292-304, 2003.

[8] G. Moncada, D. Sepúlveda, K. Elphick et al., "Effects of light activation, agent concentration, and tooth thickness on dental sensitivity after bleaching," Operative Dentistry, vol. 38, no. 5, pp. 467-476, 2013.

[9] J. F. Bortolatto, H. Pretel, M. C. Floros et al., "Low concentration $\mathrm{H}_{2} \mathrm{O}_{2}$ /TiO_N in office bleaching: a randomized clinical trial," Journal of Dental Research, vol. 93, no. 7, pp. 66S-71S, 2014.

[10] A. D. da Mata and D. N. Marques, "A novel technique for inoffice bleaching with a $6 \%$ hydrogen peroxide paint-on varnish," 
The European Journal of Esthetic Dentistry, vol. 1, no. 1, pp. 7077, 2006.

[11] A. Joiner, "The bleaching of teeth: a review of the literature," Journal of Dentistry, vol. 34, no. 7, pp. 412-419, 2006.

[12] W. Buchalla and T. Attin, "External bleaching therapy with activation by heat, light or laser-a systematic review," Dental Materials, vol. 23, no. 5, pp. 586-596, 2007.

[13] A. Reis, S. Kossatz, G. C. Martins, and A. D. Loguercio, "Efficacy of and effect on tooth sensitivity of in-office bleaching gel concentrations: a randomized clinical trial," Operative Dentistry, vol. 38, no. 4, pp. 386-393, 2013.

[14] S. E. A. Camargo, M. C. Valera, C. H. R. Camargo, M. N. Gasparoto Mancini, and M. M. Menezes, "Penetration of $38 \%$ hydrogen peroxide into the pulp chamber in bovine and human teeth submitted to office bleach technique," Journal of Endodontics, vol. 33, no. 9, pp. 1074-1077, 2007.

[15] C. A. S. Costa, H. Riehl, J. F. Kina, N. T. Sacono, and J. Hebling, "Human pulp responses to in-office tooth bleaching," Oral Surgery, Oral Medicine, Oral Pathology, Oral Radiology and Endodontology, vol. 109, no. 4, pp. e59-e64, 2010.

[16] J. Martin, E. Fernandez, V. Bahamondes et al., "Dentin hypersensitivity after teeth bleaching with in-office systems. randomized clinical trial," American Journal of Dentistry, vol. 26, no. 1, pp. 10-14, 2013.

[17] J. F. Bortolatto, T. C. Trevisan, P. S. Bernardi et al., "A novel approach for in-office tooth bleaching with $6 \% \mathrm{H}_{2} \mathrm{O}_{2} / \mathrm{TiO} \_\mathrm{N}$ and LED/laser system - a controlled, triple-blinded, randomized clinical trial," Lasers in Medical Science, vol. 31, no. 3, pp. 437-444, 2016.

[18] H. B. Dias, E. T. Carrera, J. F. Bortolatto, M. F. de Andrade, and A. N. de Souza Rastelli, "LED and low level laser therapy association in tooth bleaching using a novel low concentration $\mathrm{H}_{2} \mathrm{O}_{2}$ / $\mathrm{N}$-doped $\mathrm{TiO}_{2}$ bleaching agent," Laser Physics, vol. 26, no. 1, Article ID 015602, 2016.

[19] K. Sakai, J. Kato, H. Kurata et al., "The amounts of hydroxyl radicals generated by titanium dioxide and $3.5 \%$ hydrogen peroxide under 405-nm diode laser irradiation," Laser Physics, vol. 17, no. 8, pp. 1062-1066, 2007.

[20] T. Suemori, J. Kato, T. Nakazawa et al., "Effects of light irradiation on bleaching by a $3.5 \%$ hydrogen peroxide solution containing titanium dioxide," Laser Physics Letters, vol. 5, no. 5, pp. 379-383, 2008.

[21] H. O. Heymann, “Tooth whitening: facts and fallacies," British Dental Journal, vol. 198, no. 8, p. 514, 2005.

[22] T. Maetani, F. Yoshino, A. Yoshida et al., "An investigation of application of novel tooth bleaching using low concentration of hydrogen peroxide-dental application of electron spin resonance (ESR) technique for detecting reactive oxygen species," Oral Therapeutics and Pharmacology, vol. 27, no. 2, pp. 109-115, 2008.

[23] J. Oteo Calatayud, P. Mateos de la Varga, C. Oteo Calatayud, and M. J. Calvo Box, "Comparative clinical study of two tooth bleaching protocols with $6 \%$ hydrogen peroxide," International Journal of Dentistry, vol. 2009, Article ID 928306, 5 pages, 2009.

[24] C. Zantner, F. Derdilopoulou, P. Martus, and A. M. Kielbassa, "Randomized clinical trial on the efficacy of 2 over-the-counter whitening systems," Quintessence International, vol. 37, no. 9, pp. 695-706, 2006.

[25] N. U. Wetter, E. P. Branco, A. M. Deana, and J. E. P. Pelino, "Color differences of canines and incisors in a comparative long-term clinical trial of three bleaching systems," Lasers in Medical Science, vol. 24, no. 6, pp. 941-947, 2009. 


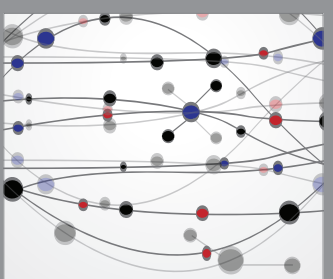

The Scientific World Journal
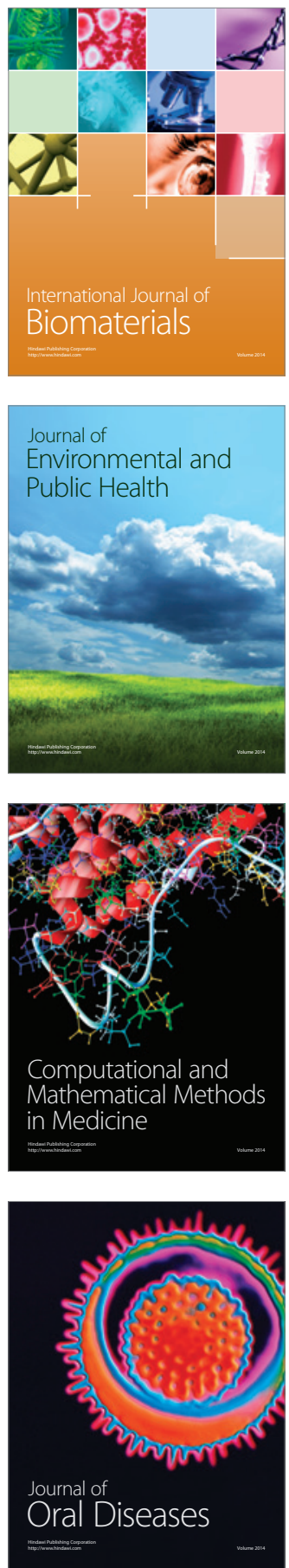
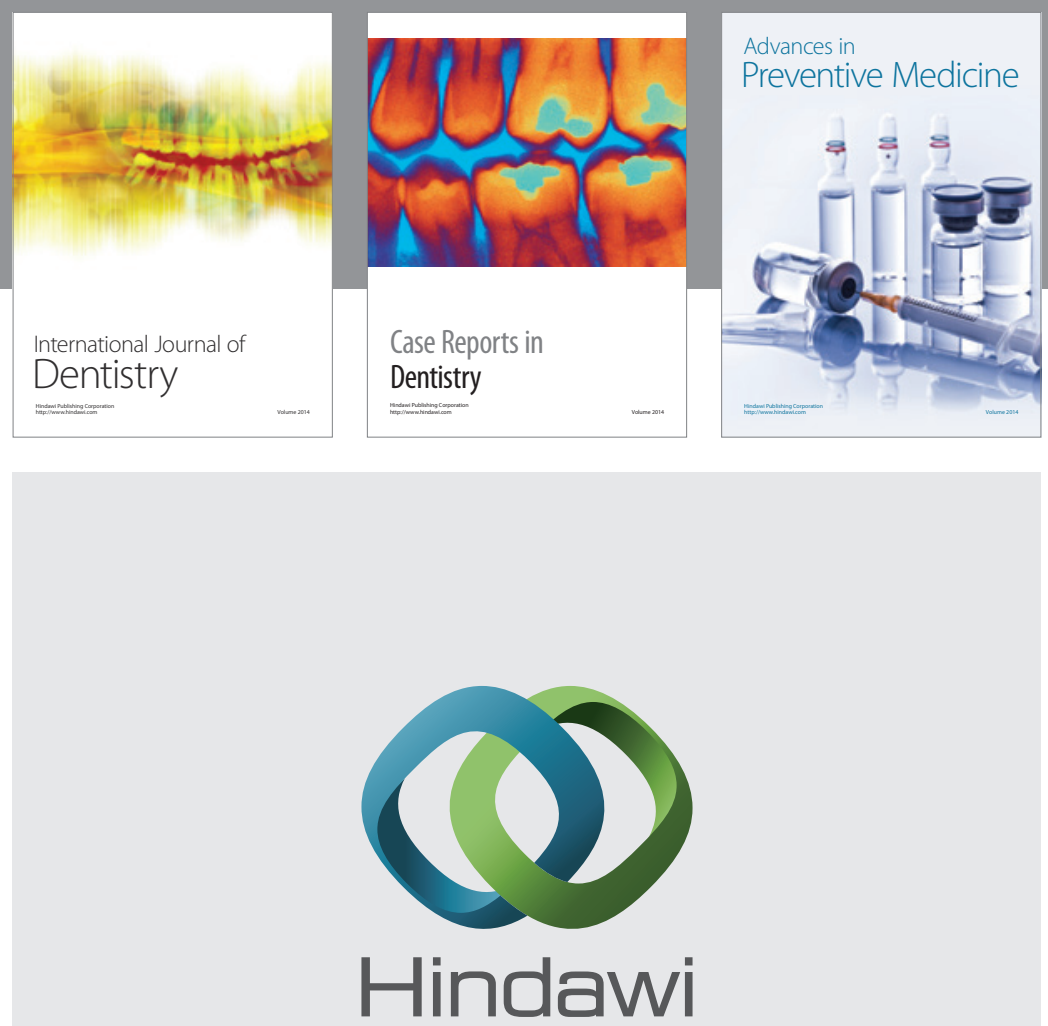

Submit your manuscripts at

http://www.hindawi.com
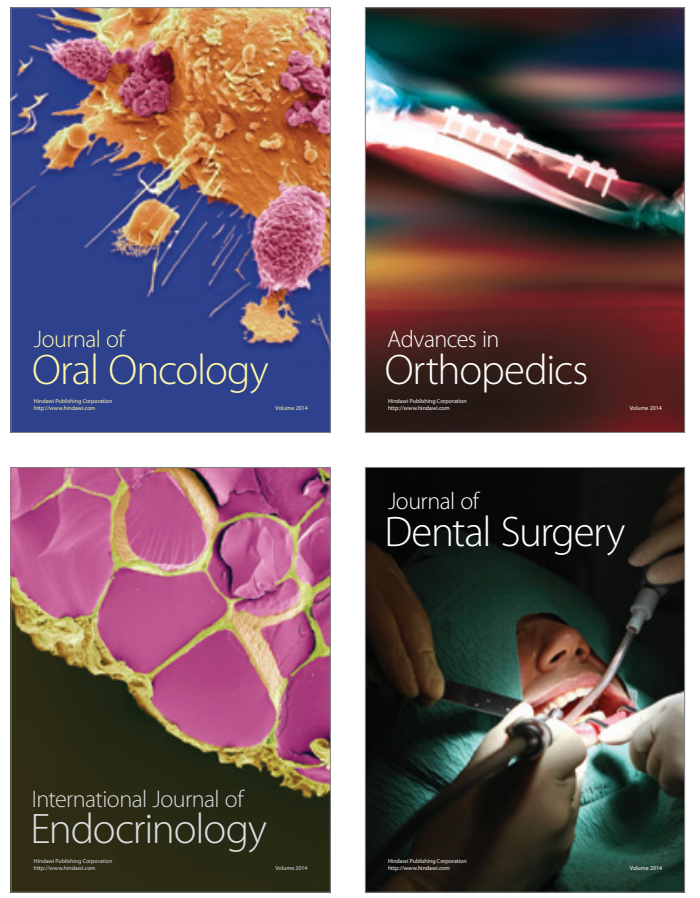
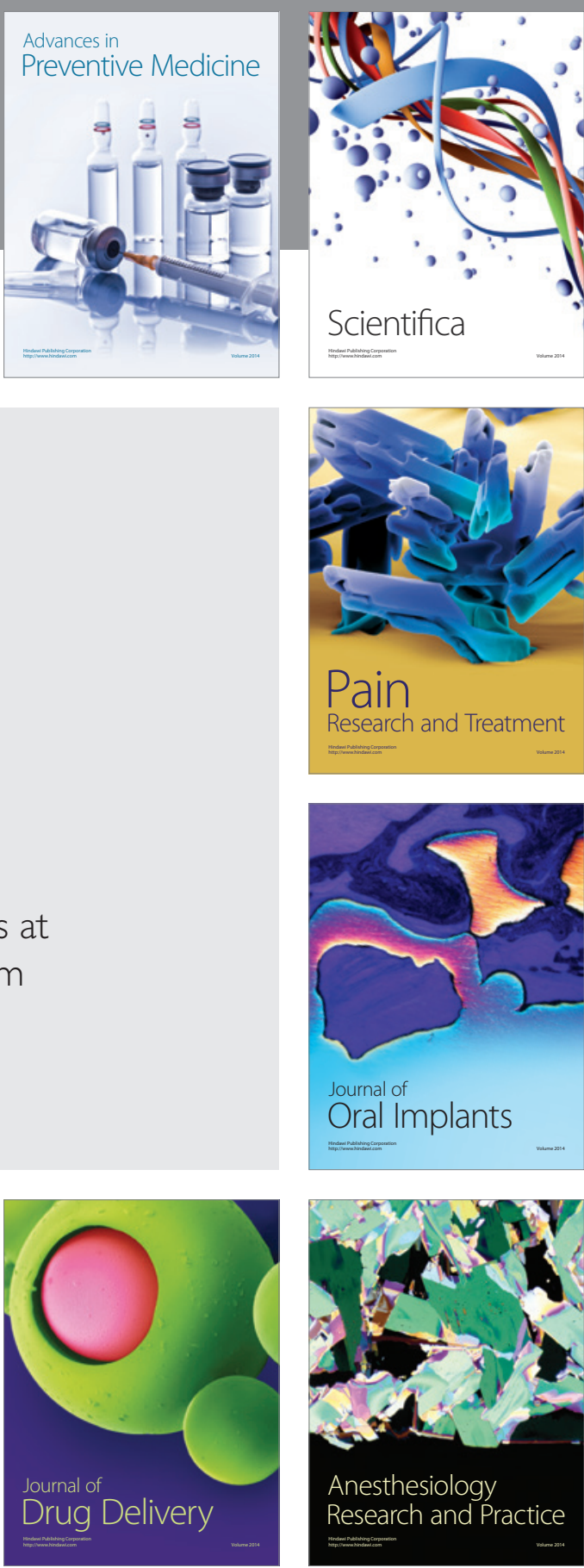

Scientifica
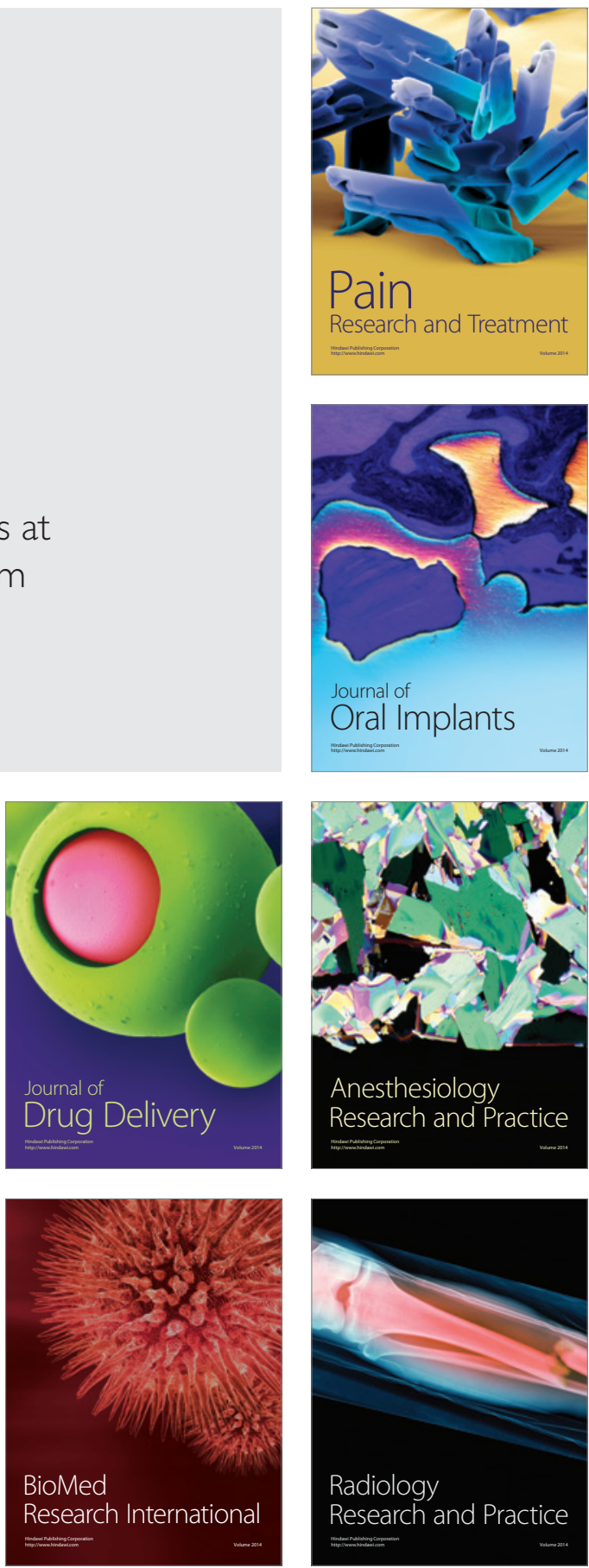